\title{
Recenzija knjige: Vrednotenje politik - Obzorja nove miselnosti
}

\author{
Aleksander Aristovnik \\ Univerza v Ljubliani, Fakulteta za upravo \\ aleksander.aristovnik@fu.uni-li.si
}

Vrednotenje politik - Obzorja nove miselnosti. Avtorii: Radej Bojan, Mojca Golobič, Mirna Macur, Srečo Dragoš. Spremna beseda: Darko Štrajn. Ljubljana: Založba Vega, 2011.

V zadnjih dveh desetletjih je $v$ večinoma naraščajočem trendu izhajalo vse več del s področja vrednotenja različnih vidikov javnih politik. Razlog za to ne more biti slučajen. Zanimanje za vrednotenje politik je povezano z vse boli sistematičnimi prizadevanji, da bi javno upravljanje postalo učinkovitejše in bi svoje cilje uresničevalo vsaj ceneje, če ne obenem tudi bolje. To je tem boli aktualno $v$ globalno spremenjenih pogojih za delovanje nacionalnih držav, katerih vlade imajo vse bolj zvezane roke, medtem pa so se njene institucije od same svoje togosti že nezdravo poredile. To so instrumentalni razlogi, ki se za vrednotenje učinkov politik zanimajo le kot orodje za "izbolišanje" javnega upravljanja.

Tej usmeritvi sledi večina novejših del z zadevnega področja, avtorii knjige pa ji nasprotujejo kot preveč pristranski, da bi z njo lahko zaobjeli izvirno poslanstvo vrednotenja politik in razloge za njegove sedanje težave. Standardni pristop k vrednotenju učinkov kot odvisnem orodju politik je za nas pomemben kot objekt kritike. Vrednotenje je mogoče zastaviti obratno kot od birokracije in od trga neodvisen vzvod spreminjanja politik. Gre za preiskovanje možnosti za porajanje takšnih pristopov k vrednotenju, ki bodo uveljavili od politike neodvisno miselnost vrednotenja, da se z njim na novo osmislijo podlage skupnega življenja in nato $v$ razširjenem miselnem okviru na novo opredelijo obstoječi, "nerešliivi" izzivi javnega upravljanja.

Doslej je razumevanje družbenih dilem dolgo počivalo na prepričanju, da so javne zadeve enostavne $v$ smislu, da oblasti do obisti 
razumejo njihove vzročno-posledične povezave in jih lahko poznavalsko upravljajo same, brez nenehnega in večinoma nadležnega vmešavanja javnosti. Tej ideji avtorii nasprotujejo in namesto nje izgradijo argument, da so javne zadeve postale kompleksne, zato smer vzročno-posledičnih povezav ni več jasna in zlasti ni več enosmerna. Zato se mora močno spremeniti tudi način obravnave javnih zadev na primer o možnostih ustreznejšega povezovanja raznorodnih prizadevanj ljudi $\vee$ prednostne vladne odločitve.

Spoznanje, da je družba postala kompleksna, pomeni, da resnica o družbenih zadevah, kot o tem kaj je skupno dobro ali o tem, kaj naj bodo prednostne naloge javnih politik in kako uspešno jih dosegajo, ni več ena sama, to je tista na oblasti, ampak o pomembnih stvareh obstaja več dobro utemeljenih in enako veljavnih resnic. Družba je $\vee$ razumevanju same sebe, $v$ ocenah svojega stanja in perspektiv razpadla na nekompatibilne poglede svojih avtonomnih podsistemov. Zahteve po avtonomiij so posledica naraščanja medsebojne soodvisnosti, kakor tudi zaradi tržne liberalizacije in tehnoloških sprememb, ki ogrožajo družbeno različnost. Z novoosvojeno avtonomijo na ravni podsistemov so politične skupnosti $v$ svojem centru razpadle in kot celote ne znajo več razmišljati celostno in tako razkrojene ne zmorejo doseči soglasja o skupno pomembnih stvareh. Na to brezizhodnost se odziva umevanje, da narava resnice o družbenih dejstvih ni več enovita, ampak je postala kompleksna. Potrebna je drugačna doktrina javnega upravlianja in vrednotenja njegovih učinkov, ki bo zagotavljala družbeno enovitost in bo hkrati ohranjala izhodiščno družbeno različnost.

Ko bomo razumeli in $v$ javnem upravljanju tudi uveljavili posledice tega, da je družba kompleksna, se bo pogled na družbo povsem spremenil, po mnenju avtorjev tako močno na bolje, da si to danes še težko predstavljamo. Družbena kompleksnost zahteva takšno obravnavanje javnih zadev, da bo doseženo sožitje med enotnostjo na ravni sistema in različnostio na ravni posameznikov in družbenih skupin. To preprosto nakazuje, da utegnemo mnoge težave javnega upravljanja rešiti zgolj s spremembo $v$ sedanjem načinu razmišljanja o družbenih dilemah, kar ne nazadnje pomeni nujnost spremembe družbenih strukturnih razmerij med tistimi, ki danes razmišljajo o izzivih javnega upravljanja.

168 Uprava, letnik IX, 3/2011 
Pričujoči prispevek je tako med redkimi prispevki s svojega področja, ki ni prvenstveno namenjen niti nosilcem politik, niti poklicnim evalvatorjem, ampak splošni javnosti in zlasti tistim, ki se z vrednotenjem učinkov politik srečujejo le občasno in $v$ povezavi z drugimi zadevami, s katerimi se sicer prvenstveno ukvarjajo. To so najprej vsi, ki se vključujejo $\checkmark$ upravljanje javnih zadev. Mednje na prvem mestu spadajo aktivisti civilne družbe, ki delujejo na področjih javnih dobrin. Naslednja večja skupina so javni uslužbenci, ki se z vrednotenjem učinkov politik srečujejo pri pripravi vsebinskih podlag za javne ukrepe in pri spremljanju učinkov že sprejetih ukrepov. Tretja skupina so vsi drugi, od študentov, novinarjev, in drugih (ne nazadnje tudi samih politikov), za katere je pomembno, da vsaj okvirno razumejo problematiko vrednotenja učinkov politik, ne zanima pa jih množica tehničnih vprašanj in formalnih zapletov, ki jo sicer nujno spremljajo. Ne nazadnje je delo namenjeno tudi evalvatorjem samim, a le če jih zanimajo temelina vprašanja vrednotenja in so zlasti pri volji izprašati tudi nekatera standardna pravila in ustaljene prakse svojega poklica.

Tako namesto receptur in nasvetov, značilnih za pedagoški, priročniški ali svetovalni format večine del o vrednotenju politik, želijo avtorii tukaj prispevati podlage za kritično oceno prevladujočih praks vrednotenja učinkov politik in nasploh doktrine javnega upravljanja, v kateri so se prakse vrednotenja $v$ zadnjih desetletjih tako razmahnile. Nijhov glavni namen tako ni opremiti bralca za praktično vrednotenje učinkov javnih politik, četudi to ni povsem izključeno, posebej z uporabo dodatno omenjene literature, ampak ga pospremiti do določenega razumevanje tega, zakaj so sedanji pristopi k vrednotenju učinkov politik in njegovi problemi takšni kakršni so. To je izhodišče, s katerega potem iščejo možne rešitve za sedanje težave vrednotenja politik, da bi z njihovo razrešitvijo lahko vrednotenje vendarle postalo zmoglijiv vzvod uveljavljanja legitimnih zahtev članov skupnosti, zlasti šibkejših in marginaliziranih kolektivnih interesov $\mathrm{v}$ zvezi z javnimi dobrinami.

Splošna javnost je kljub utemeljenim razlogom za svoje manjše zanimanje za vrednotenje politik vendarle njegov zelo pomemben in celo docela nepogrešljiv člen. Večina liudi vsak dan na neki način vrednoti različne vidike javnih politik, čeprav pri tem ne uporabljajo formalnih postopkov. Vsaj osnovno razumevanje formalnega vrednotenja politik, $\mathrm{h}$ katerem želijo prispevati, je vendarle smiselno tudi za širšo javnost, saj gre za okvir strukturiranega razmišljanja o zapletenih zadevah skupnega 
pomena. Vrednotenje učinkov lahko dosti pripomore $k$ boli konstruktivni javni razpravi o aktualnih javnih dilemah in $\mathrm{k}$ boli prodornem izražanju lastnih stališč. Vrednotenje je zmogljiv pripomoček nadzora javnosti nad oblastmi in pripomoček neposredne demokracije, ki daje vsem, ki se vključujejo $v$ procese vrednotenja, večje možnosti uveljavljanja utemeljenih stališč. A vse to je vidno že na površini, temeljni razlog za povezanost splošne javnost z vrednotenjem učinkov je globlji. Moramo ga šele razviti, ker je $\mathrm{v}$ razmerah družbene kompleksnosti povezan z drugačnim razumevanjem narave problema javnega upravljanja in njegovega vrednotenja od razumevanja, kot ga podaja dominantna doktrina novega javnega upravljanja.

Zaradi poklicnih razlogov so evalvatorii za razreševanje problemov vrednotenja prepogosto in preveč zlahka pripravljeni sklepati kompromise ter se ravnati oportuno. Tisti, ki pa se $v$ te procese vključujejo le priložnostno, so docela neobremenjeni z razlogi, zaradi katerih je vrednotenje politik danes $v$ globoki krizi. Splošno javnost vrednotenje zanima le, če so njegovi rezultati uporabni in so ji v oporo. Zato je javnost $\checkmark$ svojem povsem praktičnem zanimanju morda celo bolj dosleden sodnik ustreznosti vrednotenja kot smo vsi, ki se z njim ukvarjamo poklicno in zato dragocen sopotnik. Mnenje splošne javnosti o ustreznosti vrednotenja je ogledalo, $v$ katero bi se zaradi njegove dokajšnje nepopačenosti in zaradi nujnega vzdrževanja higiene svojega poklica morali poklicni evalvatorii in naročniki evalvaciijkih študii redno ogledovati. Da pa bi bila ogledalo in podoba $\vee$ njem čim mani popačena, mora tudi splošna javnost oziroma občasni udeleženci evalvacijskih procesov poznati ozadja in vsaj osnovno logiko vrednotenja učinkov javnih politik. Na to dokaj slabo kultivirano polje torej vstopa prispevek avtorjev.

Politično kritična civilna družba se z vrednotenjem javnih politik, s tem pojmom zajemamo vladne projekte (npr. investicijske), programe (na primer razvojne), proračune, plane (npr. prostorske) in predpise, danes srečuje še dokaj zadržano, preprosto, ker kakovost teh prizadevani še ni zadostna. Drugače je z uradniki. Na eni strani jih $v$ zadnjih letih kopica novih evropskih priporočil in navodil za vrednotenje učinkov politik s svojo zapletenostjo in zahtevnostjo spravlja $\vee$ obup. Na drugi strani morajo skladno s predpisi za vrednotenje izbirati najcenejše in pogosto najmani zainteresirane izvajalce za vrednotenje vsebinskih dilem iz domene javnega upravljanja. Ti naročnikom študii ponujajo le tisto, kar naročniki od njih znajo zahtevati, to pa je po navadi dosti manj kot potrebujejo in 
manj, kot bi bilo mogoče. Komercialni evalvatorii pogosto nimajo izkušeni s praksami ukvarjanja s trdovratnimi družbenimi problemi in tako niti sami ne vedo vedno, kaj naročniki potrebujejo. Bruseljska navodila za vrednotenje politik niti enim niti drugim niso vedno $v$ zadostno oporo in to vsaj iz dveh razlogov. Najprej zato, ker so napisana za izkušene, uporabljajo pa jih pogosto neizkušeni (najcenejši, občasni) evalvatorii, poleg tega pa je $\vee$ Sloveniji veliko primerov nestrokovnega prenašanja navodil $v$ prakso $z$ njihovim neustreznim prevajanjem, tolmačenjem in nerodno uporabo. Avtorji pa si vendarle ne prizadevajo iskati rešitev za težave vrednotenja, ki jih povzroča enoumje, ki se včasih tudi po birokratski poti skuša naprtiti kot dominantno, ampak iskati izhod iz enoumja in preizkusiti nekatere možnosti za njegovo preseganje z vračanjem vrednotenja politik $v$ roke in predvsem $v$ pluralno mentaliteto splošne javnosti.

Zametki dela so nastali kot odgovor Slovenskega društva evalvatorjev na skoraj sočasni pobudi Inštituta za politike prostora (IPoP) iz Ljubljane v vlogi vozlišča Mreže za prostor ( $v$ okviru projekta, ki ga je financiralo Ministrstvo za delo iz Evropskega socialnega sklada) in Računskega sodišča RS, v zvezi s pripravo seminarja o osnovah vrednotenja učinkov javnih politik. Društvo je obe pobudi hvaležno sprejelo, zavedajoč se velikih praznin, ki zevajo $v$ Sloveniji na tem področju in svojih nalog pri njihovem dopolnjevanju. Pri nastajanju dela je sodelovalo okoli trideset oseb v vlogi avtorjev prispevkov ali strokovnih svetovalcev. Znanstveno recenzijo dela so opravili izr. prof. dr. Majda Černič Istenič, Biotehniška fakulteta, Univerza v Ljubliani; doc. dr. Vida Mohorčič Špolar, Filozofska fakulteta, Univerza v Ljubliani; doc. dr. Aleksander Aristovnik, Fakulteta za upravo, Univerza v Ljubliani.

Delo postaja podlaga izobraževalnih programov, ki se izvajajo na Upravni akademiji in na Fakulteti za uporabne družbene študije, na Fakulteti za upravo, na Fakulteti za socialno delo, na Biotehniški fakulteti. Gradivo, ki je predstavljeno v knjigi, pri svojem delu uporabljajo na Ministrstvu za finance, Ministrstvu za okolje in prostor, Inštitutu za varovanje zdravja, na Kmetijsko gozdarski zbornici Slovenije in na Računskem sodišču RS.

Samo delo je razdeljeno na šest poglavii in sklep. Poglavia imajo nalogo z različnih zornih kotov osvetliti ožji izbor standardnih težav 
konvencionalnih pristopov $k$ vrednotenju učinkov politik in podati vsaj smer nijhovega reševanja.

Prvo poglavje se posveča spoznavanju narave javnega upravljanja in s tem povezani težavnosti vrednotenja učinkov politik. Med drugim so posledica tega, da je vrednotenje tradicionalno usposobljeno za ocenjevanje relativno enostavno zamišljenih politik in načinov njihovega učinkovanja, ki izhaja iz prevladujočega načina razmišljanja o javnih zadevah. Klasična znanost ne ponuja ustreznega okvira raziskovanja družbenih pojavov, ker slednji niso eksterno dani objekti, ampak jih konstruirajo ljudje sami in zato pri njih ni možna klasična ločitev med objektom in subjektom spoznavanja. Kako se izviti iz teh težav? To se avtorii vprašajo s stališča filozofije znanosti o razmeriu vrednotenja do družbenih vrednot in razmerju vrednotenja do resnice. Ugotovijo, da so družbene zadeve kompleksne, kar od nas zahteva kompleksen vpogled v družbene zadeve, s katerimi je treba nadomestiti sedanjo enodimenzionalno miselnost, ki javne zadeve zaznava preveč popačeno in je pri urejanju zadev skupnega pomena vir družbenega razdora.

Drugo poglavje se šele povsem posveti vrednotenju učinkov politik. Naloga tega poglavja je pregledati osnovna področja in vrste vrednotenja - od enostavnih do boli zapletenih, od takih, ki so usmerjena v preteklost in drugih, ki so namenjena vrednotenju dilem povezanih z izbirami, ki jih narekujejo naše ambicije glede prihodnosti. Izzivi vrednotenja učinkov politik so $v$ različnih vrstah vrednotenja pomembno različni. Vendar pa te razlike niso vedno pravilno upoštevane. Na primer, v javnem upravljanju in $v$ vrednotenju njegovih učinkov je razprostranjeno nekritično prenašanje uspešnih praks iz zasebnega sektorja, ki pa $\vee$ javnem sektorju privede do velikega popačenja javnih zadev. Podobno se razmeroma uspešni pristopi k vrednotenju enostavnih projektov kot nespremenjena logika prenašajo v prakse vrednotenja kompleksnih politik, ki vsebujejo desetine ali celo stotine enostavnih projektov, kar bi zahtevalo povsem drugačen način obravnave. Zaradi nepazliivih prehodov med ravnmi obravnave javnih zadev danes pri vrednotenju pogosto ne dobimo vpogleda, kako je vse z vsem povezano in kako učinkuje celostno.

$\checkmark$ tretjem poglaviu se avtorii temu in drugim standardnim problemom še dodatno posvetijo $s$ pregledom zgodovinskega razvoja pristopov $k$ vrednotenju politik. Najprej povzamejo zgodovinski pregled pristopov. Danes je najboli referenčna četrta generacija pristopov. Druga polovica 
poglavja s pomočjo slabosti prvih štirih generacii nakaže lastnosti, ki bi jih morali imeti pristopi "pete generacije", ki naj bi z uvedbo perspektive kompleksnosti bistveno prispevala $k$ izboljšanju sedanjih razmer na področju vrednotenja učinkov politik. Pri razlagi si avtorii pomagajo z nekaterimi povsem praktičnimi primeri težav vrednotenja $\vee$ Sloveniji, povezanimi npr. z obravnavo javnih dilem, ki jih spremljajo globoki konflikti, s primerom težav odločanja med binarnimi in pluralnimi javnimi alternativami, s primerom, ko težave pri vrednotenju povzročajo etične dileme javnih politik, posebej v kontekstu aktivnega vključevanja javnosti v vrednotenje in nazadnje še s primerom, ki opozarja na težave zaradi asimetričnih razmerij moči med sodelujočimi pri vrednotenju.

Osrednje, najdaljše in najbolj tehnično zasnovano je četrto poglavje. $\checkmark$ njem se predhodno pridobljeni vpogledi $\vee$ vidike krize vrednotenja $\vee$ drugem in tretjem poglavju povežejo s kritiko metodologii in postopka vrednotenja $v$ praksi. Praktično vrednotenje avtorii opišejo s sedmimi izvedbenimi koraki. V pripravljalni del vrednotenja spadajo: (a) določitev smotra, (b) izbor sodelujočih, (c) presoja programske teorije, (č) določitev okvira vrednotenja in (d) izbira evalvacijskih vprašani oziroma kriterijev vrednotenja. (e) Izvedbeno fazo vrednotenja opišejo s predstavitvijo nekaterih vodilnih metod vrednotenja (eksperimentalno metodo, presojo stroškov in koristi, vrednotenje z vprašalniki in kazalniki ter vrednotenje z matrično metodo). Posebno podrobno je obdelan vidik sinteze $v$ analitični fazi vrednotenja zbranega gradiva, ki z izhodišč kompleksnosti ne pozna enotnega skupnega imenovalca, zato evalvacijska sinteza ni trivialen problem.

Peto poglavje obravnava različne sektorske prakse vrednotenja na izbranih področjih $-v$ zdravstvu in politiki zdravja, $v$ prostoru, socialni ter kohezijski politiki in pripravi predpisov ter proračunov ter pri nekaterih drugih. Ugotavljajo, da prihaja do zgovornega preobrata $v$ pristopu $k$ vrednotenju. Najnovejši pristopi k vrednotenju postajajo vse bolj specializirani, kakor je bilo vrednotenje tudi na začetku svojega razvoja. Vendar pa specializacija danes ni več izvedena sektorsko izolirano ali ločeno po resorjih, ampak se specifična vprašanja obravnavajo vse boli strateško.

$\checkmark$ zvezi z uvodnimi zahtevami celostnega vrednotenja je treba, ugotavliajo avtorii na koncu, $k$ vrednotenju politik pristopiti sistematično in sistemsko. Razpravi o tem je namenjeno kratko šesto poglavje. Poglavje 
na grobo skicira okvire institucionalizacije sistema vrednotenja učinkov politik v Sloveniji. Za področje vrednotenja je danes značilna njegova nepovezanost in obstoj prostranih področij sivih lis, na katerih javno upravljanje še ni podvrženo vrednotenju učinkov.

Sedmo, sklepno poglavje na kratko obnovi namen priprave tega dela in povzame njegove ugotovitve ter nakaže širše konsekvence miselnih preobratov $v$ načinu razmišljanja o kompleksnih družbenih vprašanjih. Rezultati tega razmišljanja na koncu pripeliejo dlje, kot so se avtorji namenili na začetku. Z ustreznejšim vrednotenjem učinkov politik v razmerah družbene kompleksnosti se $v$ javnem upravljanju prikopliejo do temeline doktrine javnega upravljanja. Pri vrednotenju politik tako ne gre zgoli za ocenjevanje uspešnosti politik, ampak še boli za to, kako "razmišljati družbeno", kako razmišljati o izzivih, ki se tičejo nas vseh.

174 Uprava, letnik IX, 3/2011 